\title{
Classification of Sanitation Services and Students' Sanitation Practices among Schools in Lagos, Nigeria
}

\author{
Ojima Zechariah Wada ${ }^{1}$, Elizabeth O. Oloruntoba ${ }^{1}$, Mumuni Adejumo ${ }^{1}$ and Olufemi O. Aluko ${ }^{2}$ \\ ${ }^{1}$ Department of Environmental Health Sciences, Faculty of Public Health, College of Medicine, University of \\ Ibadan, Ibadan, Nigeria \\ ${ }^{2}$ Department of Community Health, Obafemi Awolowo University, Ife, Nigeria \\ Correspondence: Elizabeth O. Oloruntoba, Department of Environmental Health Sciences, Faculty of Public \\ Health, University of Ibadan, Ibadan, Nigeria. E-mail: li_zzyy@yahoo.com
}

Received: April 12, 2020

Accepted: July 6, 2020

Online Published: September 30, 2020

doi:10.5539/enrr.v10n3p55

URL: https://doi.org/10.5539/enrr.v10n3p55

\begin{abstract}
The paucity of information on the number of accessible sanitation facilities in secondary schools in developing countries has hindered efforts in attaining sustainable development in this area. Therefore, this study was designed to bridge that gap. The cross-sectional study utilized a 4-stage sampling technique to select 386 students from schools in Badagry, Lagos. Pre-tested questionnaire and observational checklists were used to obtain data. Data were analyzed using descriptive statistics and logistic regression at $5 \%$ level of significance. Respondents' mean age was $15.8 \pm 1.5$ years and $55.2 \%$ were female. On-site observation revealed that all the schools had improved sanitation facilities, while $37 \%$ of the available toilet compartments were inaccessible to the students. Majority ( $85 \%)$ of the facilities provided limited service, while $15 \%$ provided basic service. The student to toilet ratio for the public school girls and boys were 3191:1 and 642:1 respectively, while the private school had a ratio of 257:1 and 289:1 for girls and boys respectively. Some of the sanitation practices observed in the schools were open defecation (35.4\%), toilet avoidance (21\%), and prolonged urine and feacal retention (57.4\%). Students from the public school were about 3 times more likely to practice open defecation $(\mathrm{OR}=2.87 ; \mathrm{CI}=1.160-7.095)$. Also, male students were more likely to practice open defecation $(\mathrm{OR}=1.72 ; \mathrm{CI}=1.125-2.615)$. All the schools did not meet the school sanitation standard of 1 toilet to 30 boys/girls set by the Federal Government of Nigeria. Sustainable sanitation-interventions and maintenance schemes are required to safeguard the health of the students and the community at large.
\end{abstract}

Keywords: Badagry, JMP School Sanitation, Lagos, Open Defecation, Sanitation Practices, Sanitation Services, School Sanitation, Student to Toilet Ratio

\section{Introduction}

The Sustainable Development Goals (SDGs) are global road maps which aim to effectively tackle the challenges faced by the world as a whole, in order to attain a more sustainable future for all. The SDGs 6 and 4 focused on the provision of basic sanitation services in schools However, targets 6.2 emphasized the need to achieve access to adequate and equitable sanitation and hygiene for all and end open defecation, paying special attention to the needs of women and girls and those in vulnerable situations by the year 2030. Also, target $4 \mathrm{a}$ affirmed the necessity to build and upgrade education facilities that are child, disability and gender sensitive and provide safe, nonviolent, inclusive and effective learning environments for all by the year 2030 (World Health Organization/United Nations International Children's Education Fund [WHO/UNICEF], 2018). Accessibility of students to basic sanitation services at school is prerequisite for safe sanitation practice. It also plays an integral role in safeguarding the health of the public by ensuring these institutions do not become hotspots for breeding disease vectors (Adams, Jamie, Yves \& Jackie, 2009). The absence of basic sanitation services in schools has been reported to result into absenteeism, distraction and decreased enrolment, toilet avoidance and reduced school participation and performance of students (Sommer, 2010; Birdthistle, Dickson, Freeman \& Javidi, 2011; Montgomery, Ryus, Dolan, Dopson \& Scott, 2012; WHO, 2016). The female students are disproportionately affected as they require these facilities for safe menstrual hygiene management (MHM), thereby impeding their ability to reap the benefits of educational attainment (Gakidou, Cowling, Lozano \& Murray, 2010; Morrissey, Hutchison \& Winsler, 2014). 
Moreover, an estimated 1.9 billion school days are lost due to diarrhea illness and other water and sanitationrelated diseases (Hutton, Guy and Haller, 2004). The absence of safe water, poor sanitation and prevalence of unhygienic behaviours accounted for over $60 \%$ of the disease burden and was the leading cause of death among students in developing countries (Adams et al., 2009). It was estimated that 46.5 million Nigerians practice open defecation, which placed the country as the second highest globally (UNICEF, 2018). The predominant practice of open defecation by $23.5 \%$ of Nigerians has been linked to pose grave public health risks (Nigeria Demographic and Health Survey [NDHS], 2013). The Nigerian policy guideline on school sanitation of 2005 has a standard of one toilet compartment per 30 boys/30 girls (Federal Ministry of Education, 2006). However, this is not often the case as most schools do not meet up with this requirement. For instance, UNICEF in 2015 reported that the average ratio of toilets in the urban schools for girls was 1:214 and for boys 1:374 while the ratio was 1:168 and 1:272 for girls and boys respectively in rural schools (UNICEF, 2015a). Another WASH survey carried out across public schools in Lagos and Ogun State had ranges of the students to toilet ratio within 1:70 to 1:320 (Olukanni, Aridegbe, Awofeso \& Ekwulugo, 2013). The WHO and UNICEF jointly developed JMP service ladders to monitor the WASH facilities present in schools globally. The sanitation facilities were classified as improved and unimproved based on the ability of such facility to separate faeces from human contact, while the sanitation services were classified as providing either basic, limited or no service (WHO/UNICEF, 2018).

Nigeria is a country with around $72 \%$ of her population within the age bracket 0 to 24 years and a median age of 18.4 years (United Nations Population Fund Nigeria [UNFPA], 2018). This implies that for any sustainable change to be implemented, school-based interventions are integral since adolescents spend a substantial portion of their days in schools (Pilar \& Brett, 2008). Schools are important and stimulating learning environments for children and have the potential to significantly alter their behaviour patterns leading to improved hygiene practices both in school, at home and in their resident community at large (UNICEF, 2012).

A report in reference (UNICEF, 2015b) on Cholera Outbreak in West and Central Africa revealed that there were cases of cholera outbreak in Bauchi State, Benue State and Lagos State. The incidence was reported in two Local Government Areas (LGAs) in Lagos State: Badagry and Eti Osa. The report recommended that sustainable WASH services should be regularly monitored in affected LGAs. Furthermore, inaccessibility of students in developing countries to basic sanitation services has been revealed to predispose them to unsafe sanitation practices. Information on the number of accessible sanitation facilities in secondary schools is inadequate and this could hinder all the efforts in attaining sustainable development in this area. Therefore, this study was designed to document the classification of accessible sanitation services and the students' sanitation practices among secondary schools in Badagry LGA, Lagos, Nigeria.

\section{Materials and Methods}

\subsection{Study Area}

The study was carried out in Badagry LGA (Figure 1); a coastal rural settlement in Lagos State. The LGA is situated on latitude $6^{\circ} 24^{\prime} 54.07 " \mathrm{~N}$ and longitude $2^{\circ} 52^{\prime} 52.75^{\prime \prime} \mathrm{E}$. The population of Badagry residents as at the last population census in 2006 was 241,093 (Federal Republic of Nigeria Official Gazette, 2007). Badagry is 69.19 Km southeast of Lagos, $51.49 \mathrm{Km}$ west of Seme and bordered by the Gulf of Guinea to the south (Harris and Lynn, 2017). It is an agrarian society; where inhabitants majorly practice fishing, farming and animal husbandary (Egbonwon, 2018). Badagry LGA consists of 11 wards, each ward headed by a Councilor. Information about the number of secondary schools in the LGA was obtained from the Lagos State Ministry of Education; there are 13 public senior secondary schools and about 30 registered private senior secondary schools in Badagry.

\subsection{Study Design}

This is a cross-sectional study which adopted a pre-tested semi-structured questionnaire and an observational checklist to collect data. The instrument were pre-tested in a senior secondary school in Alimosho LGA. This secondary school was located in a LGA with similar characteristics to study area. A total of 40 questionnaire were administered and analyzed using Cronbach alpha while a reliability coefficient of 0.747 was obtained.

\subsection{Study Population and Sampling Procedure}

The study population included male and female students from private and public secondary schools in Badagry LGA. A 4-stage sampling method was adopted to select wards, schools, classes and 386 students from 5 private and 5 public secondary schools in Badagry LGA, Lagos. A total of 10 schools (2 from each ward) were selected. During the selection stage, 5 out of the 11 ward were selected. Only wards with eligible secondary schools (at least one government school and one private school) were included. 
To maintain confidentiality, all the government schools were labeled A1, A2, A3, A4 and A5, while their respective private schools were labeled B1, B2, B3, B4 and B5. Students' selection from each school was proportionately allocated based on the student population of all the selected schools to the proposed sample size of 386 .

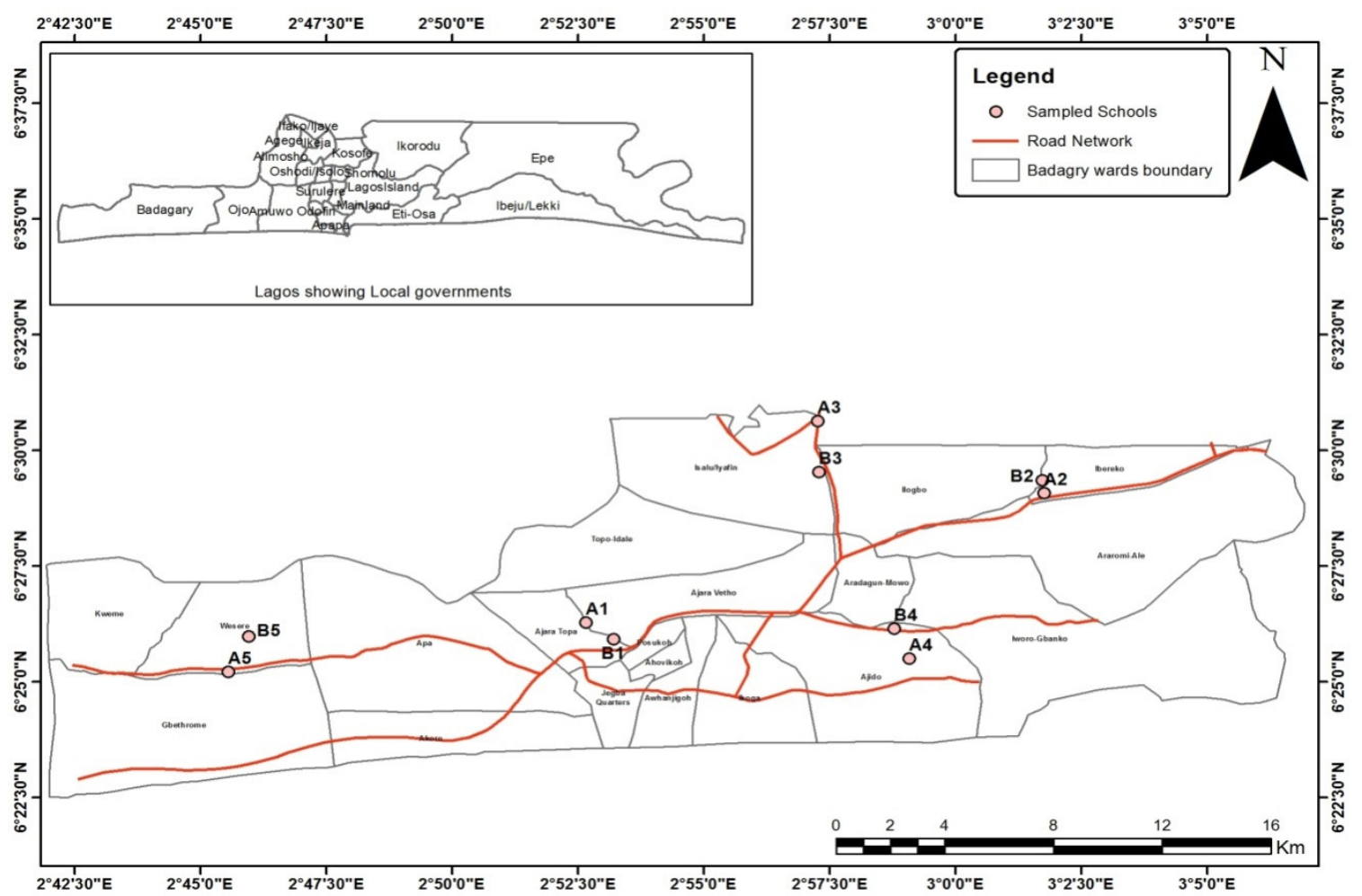

Figure 1. Map of Badagry LGA indicating sampled schools

\subsection{Data Collection instrument and Procedure}

Data were collected using self-administered questionnaire and an observational checklist. The questionnaire was a semi-structured which was adopted from core questions and indicators for monitoring SDG 6 in Schools in the Sustainable Development Goals (WHO/UNICEF, 2016). The observational checklist was adapted from WASH in Schools Monitoring Package by in reference (UNICEF, 2011) and the Nigeria Policy on School Sanitation in reference (Federal Ministry of Education, 2006).

Before the commencement of the data collection, the Lagos State Ministry of Education was visited to collect information about the schools situated in the Local Government Area. The ministry then referred the research team to the Education District V Inspectorate. The inspectorate, whose primary function is to oversee the schools in Badagry and other surrounding LGAs provided the research team with an introductory letter and contact details of the principals of the selected schools. The principals of each of the schools warmly received the research team and provided all necessary assistance. The research objectives were discussed with the principals and formal letters presented to obtain permission to carry out the work in their schools. The letters also explained the study objectives.

A total of 386 questionnaire were administered to study participants. Efforts were made to ensure the students (study participants) did not influence each other while filling out the questionnaire. Efforts were also made to ensure the teachers did not influence the students' choices. Two research assistants were trained prior to the administration of data collection so as to ensure they had a good understanding of the research objectives and the thematic areas. The training focused on the objectives and importance of the study, and how to review questionnaire to ensure completeness. The research assistants helped ensure that all the questionnaire were correctly completed by respondents by checking the questionnaire before the respondent left and errors detected were properly rectified. Data collection lasted for a period of four weeks. Of the 386 questionnaire administered, 
371 were used for the analysis (response rate of 95\%). Environmental observation data was collected from each school via the observational checklist.

\subsection{Data Management and Analysis}

Data collected were sorted and appropriately checked for completeness according to the individual schools. The questionnaire were numbered serially and data were entered and analysed using SPSS version 20. The toilets compartments were categorized as functional (toilets accessible to the students, single sex, have water available, safety doors and whole toilet seats/slabs), partially functional (toilets with no door locks or (and) broken doors or (and) no water or (and) cracked seats) and non-functional (facilities that cannot be used at all). The sanitation facilities were also classified based on the JMP school sanitation ladder into improved/unimproved facilities and basic, limited or no services (WHO/UNICEF, 2018). Analysis was conducted using descriptive statistics and inferential statistics like chi-square, correlation and logistic regression were used to measure associations between sanitation practices and socio-demographic variables at 0.05 level of significance.

\subsection{Ethical Consideration}

Ethical approval was obtained from the University of Ibadan/UCH Research Ethic Committee before the commencement of the field work of this research. Approval to carry out the study and gain access to the schools was also gotten from the Lagos State Government via the Ministry of Education, Alausa. Consent was gotten from each of the school principals who acted as in loco-parentis for the school students. Assent was also gotten from each of the study participant; there was no form of coercion. The participants and the school authorities were given assurance of confidentiality.

\section{Results}

\subsection{Socio-Demographic Characteristics of the Respondents}

Socio-demographic characteristics of the respondents are presented in Table 1. The mean age of the respondents was $15.8 \pm 1.5$ years, $55.2 \%$ of the students were female, $37.2 \%$ of the respondents' mothers and $46.3 \%$ of their fathers had tertiary education. Majority (70.5\%) of the respondents' mothers and $31.9 \%$ of their fathers engaged in trading while $57.3 \%$ were Yoruba. Majority (69.2\%) were Christians while 54\% had under-5 children in their households.

\subsection{Type of Sanitation Facilities, Their Classification and Proximity to the Nearest Classroom}

Types of sanitary facility available in the private schools were water closet $(100 \%)$. Similarly, water closet was available in the all the male toilets in the public schools, while $(80 \%)$ of the girls' toilet made use of water closet. None $(0 \%)$ of the public schools and $40 \%$ of the private schools had common use toilets (facilities not segregated by sex). All (100\%) of the toilets were connected to septic tanks and $100 \%$ of the schools had separate sanitary compartments for students and teachers. Furthermore, $36.9 \%$ of the total toilet compartments present in all the schools was unavailable for students' use, as they were permanently locked. It was observed that $83.3 \%$ of the total toilet compartments in the private schools were accessible to the students, while $56.9 \%$ of the facilities were accessible to the public school students (Figure 2). Only $24.2 \%$ of the sanitation facilities in the public schools and $20.0 \%$ in the private schools were in a functional state. Likewise, $34.6 \%$ of the accessible boys' sanitation facilities and $13.0 \%$ of the female facilities were functional.

Table 2 shows the classification of accessible toilets based on their functionality. Majority (73\%) of the sanitation facilities accessible to the students were partially functional, this accounted for $69.7 \%$ in public schools and $80 \%$ in the private schools. Comparing boys' and girls' facilities, $66.7 \%$ of the available boys' sanitation facilities and $82.6 \%$ of the female were partially functional. Only $4 \%$ of all available sanitation facilities were non-functional. Some of the challenges observed with the partially functional sanitation facilities were broken/no toilet seat (10\%), common-use toilet facilities $(20 \%)$, and facilities that were not readily accessible to the students because the toilet keys were with designated people who were not stationary (40\%). Other challenges were facilities without water to flush $(30 \%)$, facilities that did not provide privacy due to broken doors and no safety locks $(80 \%)$ as shown in Figure 3. Majority (76.2\%) of the female toilet compartments and 59.1\% of the male facilities had no safety locks (Plate 1). 
Table 1: Socio-demographic characteristics of respondents

\begin{tabular}{|c|c|c|}
\hline Characteristics & Frequency $(\mathrm{N}=371)$ & Percentage \\
\hline \multicolumn{3}{|l|}{ Sex } \\
\hline Male & 166 & 44.8 \\
\hline Female & 205 & 55.2 \\
\hline \multicolumn{3}{|l|}{ Age of respondents } \\
\hline 12 years to 16 years & 261 & 70.4 \\
\hline 17 years to 21 years & 110 & 29.6 \\
\hline \multicolumn{3}{|l|}{ Mean $\pm \mathrm{SD}=15.8 \pm 1.5$ years } \\
\hline \multicolumn{3}{|l|}{ Type of School } \\
\hline Government-owned School & 337 & 90.9 \\
\hline Private School & 34 & 9.1 \\
\hline \multicolumn{3}{|c|}{ Mother's highest level of education } \\
\hline Primary & 35 & 9.3 \\
\hline Secondary & 181 & 48.9 \\
\hline Tertiary & 138 & 37.2 \\
\hline No formal education & 17 & 4.5 \\
\hline \multicolumn{3}{|l|}{ Mother's occupation } \\
\hline Trading & 262 & 70.5 \\
\hline Civil servant & 1 & 12.7 \\
\hline Housewife & 47 & 4.1 \\
\hline \multirow[t]{2}{*}{ Self-employed } & 15 & 12.7 \\
\hline & 47 & \\
\hline \multicolumn{3}{|c|}{ Father's highest level of education } \\
\hline Primary & 24 & 6.6 \\
\hline Secondary & 165 & 44.4 \\
\hline Tertiary & 172 & 46.3 \\
\hline No formal education & 10 & 2.6 \\
\hline \multicolumn{3}{|l|}{ Father's occupation } \\
\hline Trader & 118 & 31.9 \\
\hline Civil servant & 115 & 31.1 \\
\hline Farmer & 23 & 6.1 \\
\hline Businessman & 115 & 30.9 \\
\hline \multicolumn{3}{|l|}{ Ethnic group } \\
\hline Yoruba & 213 & 57.3 \\
\hline Egun & 62 & 16.8 \\
\hline Hausa & 5 & 1.3 \\
\hline Igbo & 59 & 16.0 \\
\hline Others* & 32 & 8.6 \\
\hline \multicolumn{3}{|l|}{ Religion } \\
\hline Christianity & 257 & 69.2 \\
\hline Islam & 113 & 30.5 \\
\hline Traditional worshipper & 1 & 0.3 \\
\hline
\end{tabular}

Traditional worshipper 


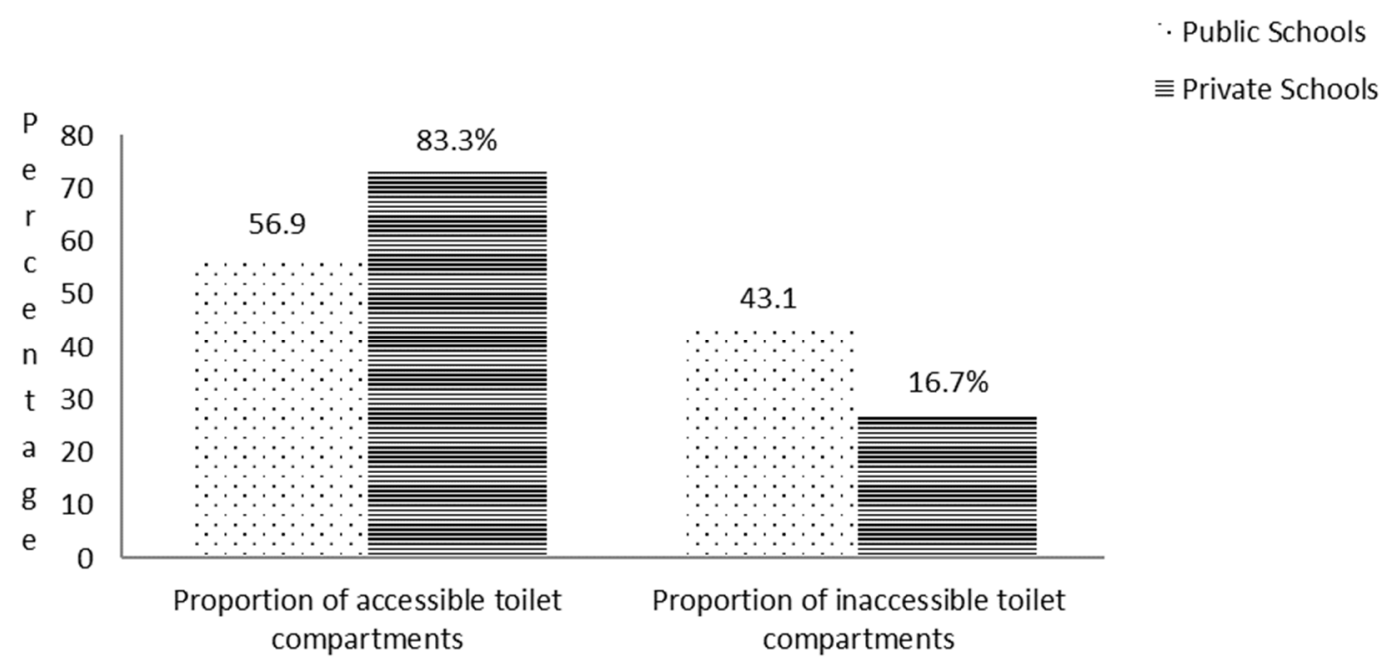

Accessibility to toilet compartments

Figure 2. Proportion of accessible and inaccessible toilet facilities between school types

Table 2. Status of school sanitation facilities based on their accessibility and services

\begin{tabular}{|c|c|c|c|c|c|c|}
\hline \multirow{2}{*}{ Number of Toilet Compartment } & \multirow{2}{*}{ School Type } & \multicolumn{4}{|c|}{ Type of Toilet Compartments } & \multirow[t]{2}{*}{ Total } \\
\hline & & Girl's Only & Boy’s Only & Urinal & Common Use & \\
\hline \multirow[t]{3}{*}{ Total Toilet Compartments Present } & Public & 27 & 27 & 4 & 0 & 58 \\
\hline & Private & 11 & 11 & 0 & 4 & 24 \\
\hline & Total & 38 & 38 & 4 & 4 & 84 \\
\hline \multirow[t]{3}{*}{ Accessible Toilet Compartments } & Public & 15 & 16 & 2 & 0 & 33 \\
\hline & Private & 8 & 8 & 0 & 4 & 20 \\
\hline & Total & 23 & 24 & 2 & 4 & 53 \\
\hline Functional Accessible & Public & 1 & 5 & 2 & 0 & 8 \\
\hline \multirow{2}{*}{ Toilets } & Private & 2 & 2 & 0 & 0 & 4 \\
\hline & Total & 3 & 7 & 2 & 0 & 12 \\
\hline \multirow[t]{3}{*}{ Partially Functional Toilets } & Public & 13 & 10 & 0 & 0 & 23 \\
\hline & Private & 6 & 6 & 0 & 4 & 16 \\
\hline & Total & 19 & 16 & 0 & 4 & 39 \\
\hline \multirow[t]{3}{*}{ Non-functional Accessible Toilets } & Public & 1 & 1 & 0 & 0 & 2 \\
\hline & Private & 0 & 0 & 0 & 0 & 0 \\
\hline & Total & 1 & 1 & 0 & 0 & 2 \\
\hline
\end{tabular}

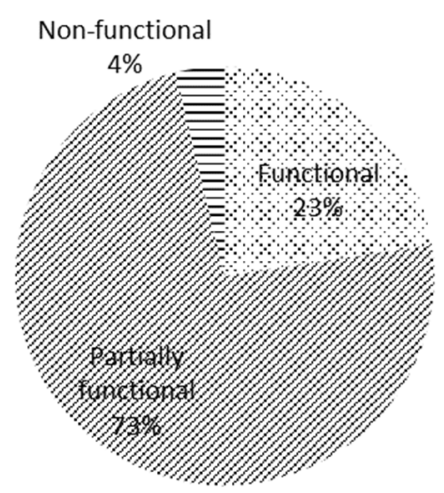


Figure 3. Proportion of accessible sanitation facilities based on their functionality
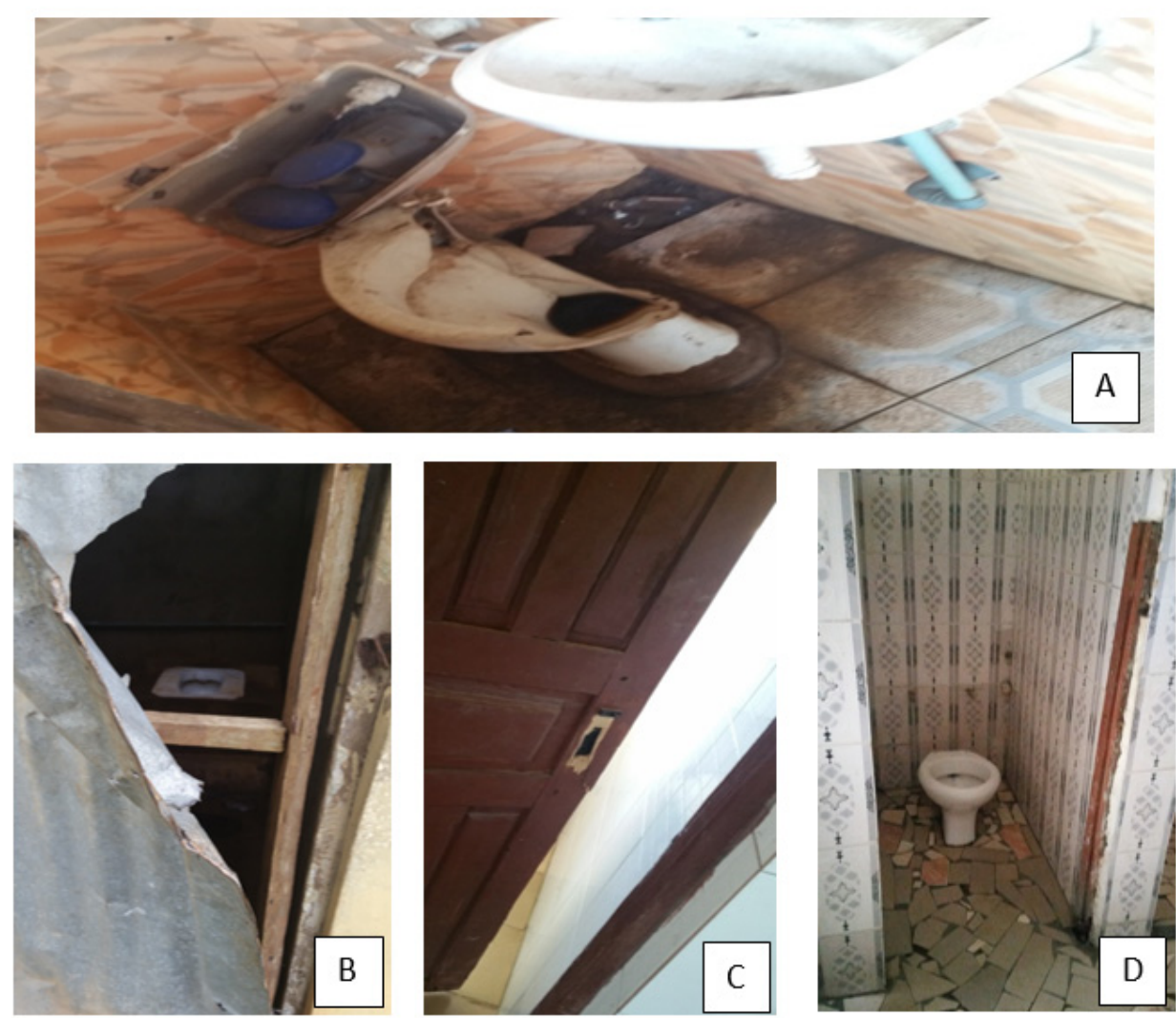

Plate 1. Some partially functional sanitation facilities (A- Broken toilet; B- Toilet lacking privacy; C- Door with no safety locks; D- Broken door)

\subsection{Proximity of Toilets to the Nearest Classroom}

The mean (average) distance of the toilet facilities to the nearest classroom was $26.20 \mathrm{~m} \pm 27.34$ in both public and private schools. The mean distance of the public school toilet facilities to the nearest classroom was $42.70 \mathrm{~m}$ \pm 30.52 while that of the private schools was $9.70 \mathrm{~m} \pm 6.51$. Details are shown in Table 3 .

Table 3. Distance between the toilets and nearest classrooms

\begin{tabular}{llll}
\hline & \multicolumn{2}{l}{ Average Distance to Nearest Classroom (Meters) } & Mean Distance (m) \\
\hline Type of Schools & Girl's Only & Boy’s Only & \\
Public Schools & $50.60 \pm 34.92$ & $34.80 \pm 26.81$ & $42.70 \pm 30.52$ \\
Private Schools & $10.90 \pm 7.06$ & $8.50 \pm 6.48$ & $9.70 \pm 6.51$ \\
Mean Distance(m) & $30.75 \pm 31.65$ & $21.65 \pm 23.03$ & $26.20 \pm 27.34$ \\
\hline
\end{tabular}

\subsection{Reported Sanitation Practice during the School Hours}

Respondents' sanitation practice during the school hours is presented in Table 4. It was revealed that $58.0 \%$ students stated that they routinely defecate in the school toilets, $21.1 \%$ said they routinely used the bush, field and other outdoor environment while $20.9 \%$ said they practiced toilet avoidance. It was revealed that $35.4 \%$ of the students reported that they practice open defecation while none $(0.0 \%)$ of the public schools and $20 \%$ of the private school were open defecation free (ODF), (Figure 4). The major challenges experienced by students from open defecation practices at school were violent attack and injuries (29\%) and loss of hours due to their inaccessibility to sanitation facilities (21.1\%). More than half (57.4\%) of the students revealed that they have experienced long urine and faecal retention time at school due to their inability to use the school toilets. Furthermore, (50.1\%) 
students in public schools reported that students are in in-charge of cleaning the toilets while $88.2 \%$ of the private school respondents said cleaners employed by the schools are those responsible for keeping the school toilets clean.

Table 4. Respondents' sanitation practices

\begin{tabular}{|c|c|c|}
\hline Sanitation Practice & Frequency $(\mathrm{N}=371)$ & Proportion \\
\hline \multicolumn{3}{|l|}{ Places sanitation activities were practiced } \\
\hline School toilet & 216 & 58.0 \\
\hline In the bush, field, stream, behind toilet & 78 & 21.1 \\
\hline I do not ease myself while at school & 78 & 20.9 \\
\hline Practice of Open Defecation & 131 & 35.4 \\
\hline Locations for Open Defecation Practice & $\mathrm{N}=131$ & \\
\hline Bush & 51 & 39.0 \\
\hline Lagoon/stream & 8 & 5.9 \\
\hline Behind the toilet & 37 & 28.7 \\
\hline Uncompleted building, Fields, Shot-put & 35 & 26.5 \\
\hline Experienced an accident or attack during open defecation practice & 38 & 29.0 \\
\hline Loss of learning hours via missed classes due to inaccessibility to basic sanitation services & 78 & 21.1 \\
\hline Long bowel and bladder retention time due to inaccessibility to basic sanitation services & 213 & 57.4 \\
\hline \multicolumn{3}{|l|}{ Personnel in-charge of cleaning school toilet/latrine } \\
\hline Students & 173 & 46.5 \\
\hline Teachers & 3 & 0.8 \\
\hline Cleaners & 191 & 51.4 \\
\hline Students and cleaners & 5 & 1.3 \\
\hline Availability of classes that teach sanitation and hygiene & 272 & 73.3 \\
\hline Availability of water within the school toilet & 252 & 67.8 \\
\hline Location of alternative sources of water for toilets & $\mathrm{N}=119$ & \\
\hline Within the school compound & 75 & 62.9 \\
\hline Outside the school compound & 11 & 9.7 \\
\hline Within and outside school compound & 8 & 6.5 \\
\hline There is no other option & 25 & 21.0 \\
\hline Practice of open burning for waste management & 196 & 52.9 \\
\hline
\end{tabular}

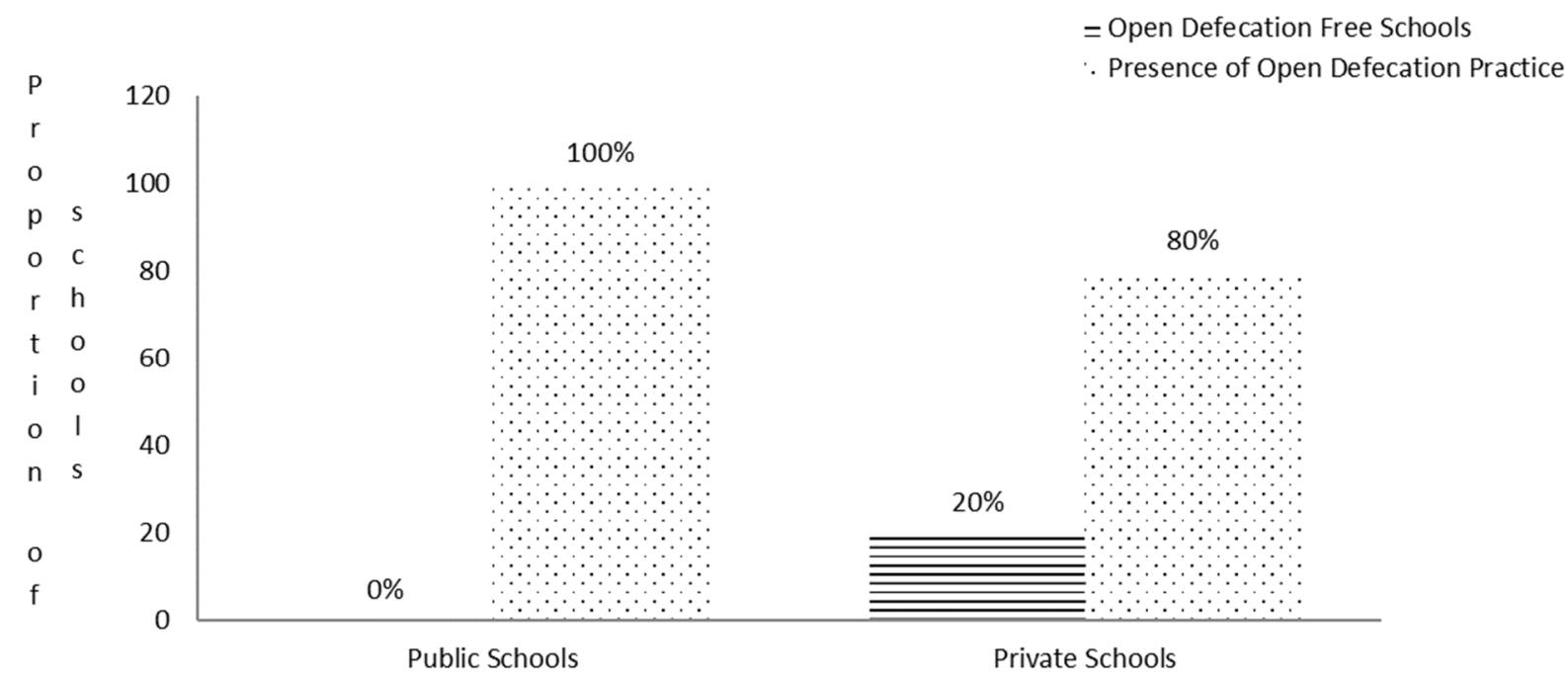

Type of School

Figure 4. Proportion of schools that were ODF

\subsection{Association between Open Defecation Practice and Socio-Demographic Variables/Loss of Learning Hours}

Association between open defecation practices, socio-demographic variables and loss of learning hours are shown in Table 5. The table revealed a statistical significant relationship between open defecation practice and type of 
school $(\mathrm{p}=0.018)$. The type of schools the respondents attended significantly affected their open defecation practice. The rate of open defecation was significantly higher in public schools $(37.2 \%)$ compared to private schools (17.1\%). Similarly, a statistically significant association existed between open defecation practice and sex of respondents $(\mathrm{p}=0.012)$. A significantly higher proportion $(42.2 \%)$ of male respondents practiced open defecation compared to $29.9 \%$ of the female respondents. The relationship between open defecation practice and their parents' highest level of education was not significant. There was a statistically significant relationship between the practice of open defecation and the age of the respondents $(\mathrm{p}=0.019)$. A significantly higher proportion $(43.8 \%)$ of older respondents (17 to 21 years) engaged in the practice as opposed to $31.2 \%$ of the younger respondents (12 to 16 years). Likewise, there was statistically significant association between the practice of open defecation and the respondents' loss of learning hours.

Logistic regression indicted that participants from the public school were about 3 times more likely to practice open defecation compared to their private school counterpart $(\mathrm{OR}=2.87$; $\mathrm{CI}=1.160-7.095)$. Also, male secondary school students were more likely to practice open defecation during the school hours compared to their female counterpart $(\mathrm{OR}=1.72 ; \mathrm{CI}=1.125-2.615)$. students who reported loss of learning hours were two times more likely to practice open defecation compare to those who did not loss learning hours $((\mathrm{OR}=2.1 ; \mathrm{CI}=1.269-3.465)$.

Table 5. Association between practice of open defecation at school and socio-demographic variables

\begin{tabular}{|c|c|c|c|c|}
\hline \multirow[t]{2}{*}{ Variables } & \multicolumn{2}{|c|}{ Open Defecation Practice } & \multirow[t]{2}{*}{$\chi^{2}$ (P value) } & \multirow[t]{2}{*}{ OR $\quad(95 \% \mathrm{CI})$} \\
\hline & Yes $(\%)$ & No (\%) & & \\
\hline \multicolumn{5}{|l|}{ Type of School } \\
\hline Public & $125(37.2)$ & $212(62.8 \%)$ & $5.62\left(0.018^{*}\right)$ & 2.87 \\
\hline Private & $6(17.1)$ & $28(82.9 \%)$ & & $(1.160-7.095)$ \\
\hline \multicolumn{5}{|l|}{ Sex of Respondent } \\
\hline Male & $70(42.2)$ & $97(57.8 \%)$ & $6.33(0.012 *)$ & 1.72 \\
\hline Female & $61(29.9)$ & $143(70.1 \%)$ & & $(1.125-2.615)$ \\
\hline \multicolumn{5}{|c|}{$\begin{array}{l}\text { Father's Highest Level of } \\
\text { Education }\end{array}$} \\
\hline No Formal/Primary & $12(35.3)$ & $22(64.7 \%)$ & $3.21(0.201)$ & - \\
\hline Secondary & $66(40.1)$ & $99(59.9 \%)$ & & \\
\hline Tertiary & $53(30.9)$ & $119(69.1 \%)$ & & \\
\hline \multicolumn{5}{|c|}{$\begin{array}{l}\text { Mother's Highest Level of } \\
\text { Education }\end{array}$} \\
\hline No Formal/Primary & $25(41.9)$ & $35(58.1 \%)$ & $2.66(0.264)$ & - \\
\hline Secondary & $65(36.8)$ & $111(63.2 \%)$ & & \\
\hline Tertiary & $41(30.7)$ & $94(69.3 \%)$ & & \\
\hline \multicolumn{5}{|l|}{ Age of Respondents } \\
\hline 12 to 16 years & $81(31.2)$ & $179(68.8 \%)$ & $5.46(0.019 *)$ & 0.58 \\
\hline 17 to 21 years & $49(43.8)$ & $62(56.2 \%)$ & & $(0.369-0.919)$ \\
\hline \multicolumn{5}{|c|}{ Loss of Learning Hours } \\
\hline Yes & $39(48.8)$ & $40(51.2)$ & $8.54\left(0.003^{* *}\right)$ & 2.10 \\
\hline No & $91(31.2)$ & $201(68.8)$ & & $(1.269-3.465)$ \\
\hline
\end{tabular}

OR- Odds Ratio

CI- Confidence interval

** significant at $\mathrm{p}<0.01 ; *$ significant at $\mathrm{p}<0.05$

\subsection{JMP Ladder for Sanitation and Students to Toilet Ratioin Schools in Badagry LGA}

On site observation revealed that all the schools had improved sanitation facilities while $15 \%$ of schools had at least a facility that provided basic service. The sanitation classification for each school is outlined in Table 6 , while Figure 5 reveals the JMP school sanitation ladder for Badagry LGA. Furthermore, there were a total of 7494 students in all the schools. The private schools consisted of 577 and 514 male and female students respectively, while the public schools consisted of 3,212 and 3,191 male and female students respectively. Only sanitation facilities that provided basic service was used to estimating the student to toilet ratio. the student to toilet ratio for male students were 289:1 (private school) and 642:1 (public school) while that of females were 257:1 (private school) to 3191:1 (public school) respectively. However, when facilities that provided basic and limited services were used to estimate the ratio, the student to toilet ratio reduced significantly. The student to toilet ratio for public 
schools became 189:1 for males and 228:1 for females, while the ratio for the private schools reduced to $58: 1$ for males and 51:1 for females (Table 7).

Table 6. JMP classification of sanitation facilities

\begin{tabular}{|c|c|c|c|c|c|}
\hline $\begin{array}{l}\text { Type of } \\
\text { School }\end{array}$ & $\begin{array}{l}\text { Name of } \\
\text { School }\end{array}$ & Type of Toilets & $\begin{array}{l}\text { Type of Sanitation } \\
\text { Facility }\end{array}$ & $\begin{array}{l}\text { JMP } \\
\text { Classification }\end{array}$ & $\begin{array}{l}\text { Reason(s) for Limited } \\
\text { Service }\end{array}$ \\
\hline \multirow{6}{*}{ Public } & A1 & Water closet & Improved & Limited & $\begin{array}{l}\text { Broken toilet seat, no } \\
\text { privacy }\end{array}$ \\
\hline & A2 & Water closet & Improved & Limited & $\begin{array}{l}\text { Inaccessibility, no water, } \\
\text { no privacy }\end{array}$ \\
\hline & A3 & $\begin{array}{l}\text { Water closet (Boys)/Pour } \\
\text { Flush (Girls) }\end{array}$ & Improved & Basic/Limited & No water, no privacy \\
\hline & A4 & Water closet & Improved & Limited & Inaccessibility, no privacy \\
\hline & A5 & Water closet & Improved & Limited & Inaccessibility, no privacy \\
\hline & B1 & Water closet & Improved & Limited & $\begin{array}{l}\text { Common-use toilets, no } \\
\text { privacy }\end{array}$ \\
\hline \multirow[t]{4}{*}{ Private } & $\mathrm{B} 2$ & Water closet & Improved & Limited & $\begin{array}{l}\text { Common use toilets, no } \\
\text { water }\end{array}$ \\
\hline & B3 & Water closet & Improved & Basic & - \\
\hline & B4 & Water closet & Improved & Limited & No privacy \\
\hline & B5 & Water closet & Improved & Limited & Inaccessibility, no privacy \\
\hline
\end{tabular}

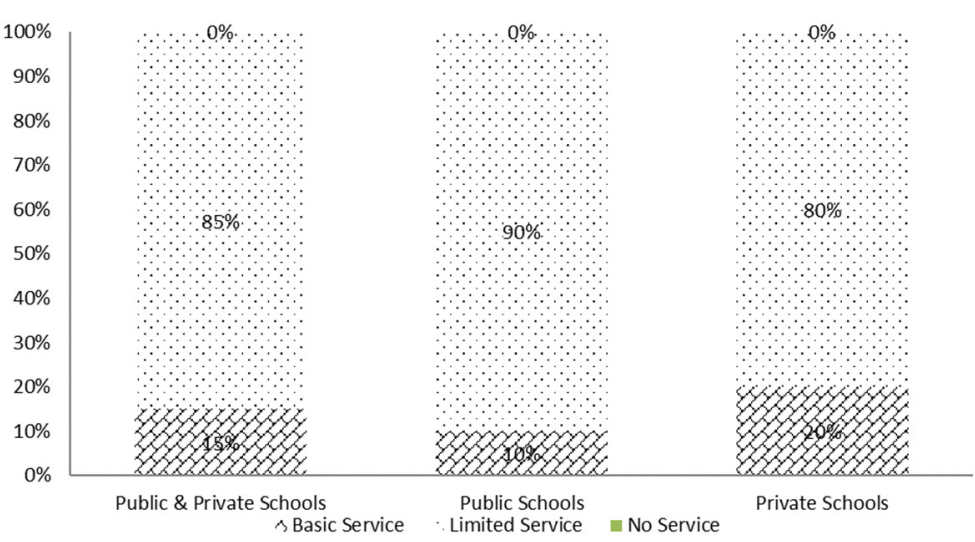

Figure 5. JMP School Sanitation Ladder for Badagry LGA Schools

Table 7. Student to toilet ratio across all schools

\begin{tabular}{|c|c|c|c|c|c|c|}
\hline \multirow[t]{2}{*}{ School } & \multirow[t]{2}{*}{$\begin{array}{l}\text { Total Student } \\
\text { Population } \\
\end{array}$} & \multirow[t]{2}{*}{$\begin{array}{l}\text { Boys to Girls } \\
\text { Ratio } \\
\end{array}$} & \multicolumn{2}{|c|}{$\begin{array}{l}\text { Sanitation facilities providing basic and } \\
\text { limited services }\end{array}$} & \multicolumn{2}{|c|}{$\begin{array}{l}\text { Student to toilet } \\
\text { ratio }\end{array}$} \\
\hline & & & Boy & Girl & Boy & Girl \\
\hline A1 & 756 & $375: 381$ & 1 & 1 & $375: 1$ & $381: 1$ \\
\hline A2 & 2168 & $1112: 1056$ & 4 & 4 & $284: 1$ & $264: 1$ \\
\hline A3 & 1335 & $685: 650$ & 3 & 2 & $228: 1$ & $325: 1$ \\
\hline A4 & 1037 & $495: 542$ & 4 & 4 & $124: 1$ & $136: 1$ \\
\hline A5 & 1107 & $545: 562$ & 4 & 4 & $136: 1$ & $141: 1$ \\
\hline $\mathrm{B} 1 * * 1$ & 182 & $91: 91$ & 2 & 2 & $46: 1$ & $46: 1$ \\
\hline $\mathrm{B} 2 * * 3$ & 210 & $126: 84$ & 0 & 0 & $* 70: 1$ & $* 70: 1$ \\
\hline B3 & 251 & $138: 113$ & 2 & 2 & $69: 1$ & $57: 1$ \\
\hline B4 & 260 & $128: 132$ & 2 & 2 & $64: 1$ & $66: 1$ \\
\hline \multirow[t]{2}{*}{ B5 } & 188 & $94: 94$ & 2 & 2 & $47: 1$ & $47: 1$ \\
\hline & & & Sanitation Facilit & g Basic Service & $\begin{array}{l}\text { Student } \\
\text { Ratio }\end{array}$ & to Toilet \\
\hline $\begin{array}{l}\text { Public } \\
\text { School }\end{array}$ & 6403 & $3212: 3191$ & 5 & 1 & $642: 1$ & 3191:1 \\
\hline $\begin{array}{l}\text { Private } \\
\text { School }\end{array}$ & 1091 & $577: 514$ & 2 & 2 & 289:1 & $257: 1$ \\
\hline
\end{tabular}

**1: this implies that school B1 has 1common use toilet

**3: this implies that school B2 has 3 common use toilets; the ratio would be 70:1 if sex is not used as a criteria 


\section{Discussion}

This study revealed that all the schools had improved sanitation facilities consisting of majorly water-closets and pour-flush latrines connected to septic tanks. This result differs from the reports of previous studies on school water and sanitation survey which revealed that majority of the schools used pit latrine (Ana, Oloruntoba \& Shendell, 2011; Egbinola \& Amanambu, 2015). The prevalence of common use toilets in the $40 \%$ of the private schools in the study area as opposed to the recommended single-sex toilet has also been reported in other Nigerian school-sanitation studies. A WASH assessment conducted across public schools in Southwestern Nigeria, reported that only $40 \%$ of the schools surveyed made use of single-sex toilets (Olukanni et al., 2013). Another assessment conducted across secondary schools in Jos North LGA also revealed that $45.3 \%$ of the toilet facilities were not segregated by sex (Agbo, Envuladu, Adah \& Zoakah, 2012). This makes the condition among public schools in Badagry LGA much better, as all the public schools had single-sex toilets. Single-sex toilets in schools protect the privacy and dignity of the students. Recent information on the prevalence of single-sex toilets across secondary schools in Nigeria is inadequate. However, the prevalence across other African countries were Mali (20\%), Togo (28\%), Niger (44\%), Uganda (86\%), Zimbabwe (98\%) and Ivory Coast (100\%) (WHO/UNICEF, 2018).

Data from this study found that $37 \%$ of the sanitation facilities were shut by the school authorities for reasons like reservation for future purpose. This shows that there is lack of understanding about the importance of ensuring the students have access to adequate sanitation facilities. This situation was prevalent in the government schools as they had $43.1 \%$ of their facilities unavailable for student use. This had a great negative impact on the student to toilet ratio and put undue pressure on the available facilities. Moreover, large proportion $(70 \%)$ of the toilet compartments was partially functional. Some of the factors that limited the functionality of the sanitation facilities such as the unavailability of functional locks on toilet doors, presence of common-use facilities and the absence of water have also been reported in some Nigerian school sanitation surveys (UNICEF, 2015a; Olukanni et al., 2013; Egbinola \& Amanambu, 2015). It can be inferred that the absence of sustainable maintenance schemes is a significant limiting factor.

Furthermore, this study shows that sanitation facilities in the schools were poor and inadequate. This was evident as some students exhibited unsafe sanitation practices. These practices include non-use of the school toilets, open defecation, toilet avoidance and moments of prolonged urine and feacal retention. Also, less proportion (20\%) of the schools were open defecation free, this affirmed how poor and inadequate the sanitation facilities in the schools were. The implications of the unsafe sanitation practices has been reported to increase susceptibility of the students to diarrhoeal and other sanitation-related diseases, increase the risk of injury or attack during practice of open defecation and reduce school participation (Adams et al., 2009; Sommer, 2010; Hutton, Guy \& Haller, 2004). Over $20 \%$ of the students in this study reported to have lost learning hours due to the sanitation inadequacies, while about $30 \%$ of those that practiced open defecation revealed that they have been subjected to harm during the act. Unsafe sanitation practices like open defecation at school could encourage the students to imbibe negative sanitation-attitude, which could be passed from one generation to the next (UNICEF, 2012).

The practice of open defecation was significantly associated with the type of school attended. Students in public schools were about 3 times more likely to engage in the act when compared to private school students. This is similar to studies that have reported open defecation practice disparities between wealth quintiles (NDHS, 2013). There were also statistically significant associations between the practice of open defecation and both the sex and the age of students. The male students were 2 times more likely to engage in the practice compared to the females, while the older students (17-21 years) were also 2 times more likely to engage in the practice. The statistically significant association derived between the practice of open defecation and loss of learning hours, is in tandem with other studies that have reported reduced school participation as a consequence of inadequate school sanitation facilities (Birdthistle et al., 2011; Montgomery P. Ryus C. R., Dolan C. S., Dopson S. \& Scott , 2012). Students that practiced open defecation were 2 times more likely to lose learning hours compared to those that did not engage in the practice.

With all the schools having at least an improved sanitation facility providing limited service to the students, the condition in the secondary schools in Badagry LGA is better compared to the national school WASH estimates which reported that $50 \%$ of the Nigerian schools provided limited sanitation service, with the remainder provided no service. However, this falls short of global standards where $66 \%$ of schools had basic sanitation service, $12 \%$ with limited service and 23\% with no sanitation service (WHO/UNICEF, 2018). The limitation in the sanitation service provided could be checked by developing a sustainable maintenance culture. If all the toilet compartment doors, locks and water supply systems were adequately maintained, majority of the schools would have provided basic sanitation services to the students. 
In this study, none of the schools met up with the 30 boys/girls to 1 toilet and 30 boys to 1 toilet or 25 girls to 1 toilet standards outlined by the Nigerian Government and WHO respectively (Adams et al., 2009; Federal Ministry of Education, 2006). The situation was far from satisfactory. Clear disparities were observed between the boy's and girl's facilities, and the private and public school facilities; the student to toilet ratio was lower for the boys compared to the girls, the ratio was also lower for the private schools compared to the public schools. Other studies have also had similar results where none of the schools met the recommended standards (UNICEF, 2015a, Olukanni et al., 2013; Agbo et al., 2012). However, a survey conducted across schools in Maiduguri reported toilet to student ratios between the ranges of 1:11 to 1:387 (Mustapha, Moses \& Muhammad, 2017).

\section{Conclusion}

The presence of improved sanitation facilities in all the schools is a notable progress. However, this was marred by the poor maintenance culture, limited accessibility and inadequacy of the sanitation facilities. The government schools had a higher proportion of inaccessible toilets, as close to half of the facilities were locked up for reasons ranging from toilets not being in good conditions and principals locking up the toilets for future use. Even though the presence of common-use toilets (toilets not segregated by sex) is against the Nigerian Policy on School Sanitation and WHO/UNICEF JMP standards, a significant proportion of the private schools had common-use toilets. More research is required to understand how widespread unsafe sanitation practice is across secondary schools in Nigeria. The condition of the sanitation facilities in the secondary schools of Badagry LGA clearly indicates that a lot of work needs to be done in order to meet the related SDG targets. Stakeholder like the Federal, State and Local Government, NGOs, Private agencies, researchers, communities, parents and individuals need join hands to ensure our schools provide adequate basic sanitation service. Future sanitation projects need to ensure the disparities observed between public and private schools, teachers' and students' and the public school boys' and girls' toilet facilities need to be bridged. Subsequent interventions also need to be socially inclusive by catering for disabled students.

\section{Acknowledgement}

We acknowledge the assistance of the personnel of the Lagos State Ministry of Education, member of the Environmental Health Unit of the Nigerian Army School of Medical Sciences Ojo Cantonment and personnel of Environmental Health Sciences Laboratory UCH.

\section{Conflict of interest}

The authors declare no conflict of interest.

\section{Data availability statement}

The data that support the findings of this study are available from the corresponding author upon reasonable request.

\section{References}

Adams, J., Jamie B., Yves C., \& Jackie S. (2009). Water, sanitation and hygiene standards for schools in low-cost settings. WHO Library Cataloguing-in-Publication. Retrieved from https://www.who.int/water_sanitation_health/publications/wash_standards_school.pdf?ua $=1$

Agbo, H. A., Envuladu, E. A., Adah, U. G., \& Zoakah, A. I. (2012). An assessment of toilet facilities in secondary schools in Jos North Local Government Area of Plateau State. Greener Journal of Educational Research, 2(4), 91-94.

Ana, G. R. E. E., Oloruntoba, E. O., Shendell, D. G., Elemile O. O., Benjamin O. R., \& Sridhar M. K. C. (2011). Solid Waste Management Problems in Secondary Schools in Ibadan, Nigeria. Journal of Environmental Health, 74(2), 24-28.

Birdthistle, I., Dickson, K., Freeman, M., \& Javidi, L. (2011). What Impact does the Provision of Separate Toilets for Girls at Schools Have on Their Primary and Secondary School Enrolment, attendance and completion?: A systemic review of the evidence. London: EPPI-Centre, Social Science Research Unit, Institute of Education, University of London.

Egbinola, C. N., \& Amanambu, A. C. (2015). Water supply, sanitation and hygiene education in secondary schools in Ibadan, Nigeria. Socio-economic Series, 29, 31-46. https://doi.org/10.1515/bog-2015-0023
Egbonwon, D. (2018). History of Badagry
in Lagos State
Nigeria. Retrieved from https://infoguidenigeria.com/history-of badagryas 
Federal Ministry of Education. (2006). Implementating Guidelines on National School Health Programme. Retrieved from https://hgsf-global.org/en/bank/downloads/doc_details/395-implementing-guidelines-onnational-school-health-programme

Gazette, F. G. N. (2007). Legal Notice on Publication of the Details of the Breakdown of the National and State Provisional Totals 2006 Census. Federal Republic of Nigeria Official Gazette, 94(24).

Gakidou, E., Cowling, K., Lozano, R., \& Murray, C. J. (2010). Increased educational attainment and its effect on child mortality in 175 countries between 1970 and 2009: a systematic analysis. Lancet, 376, 959-974. doi: 10.1016/S0140-6736(10)61257-3.

Harris, L. (Ed.). (2017). Sea ports and sea power: African maritime cultural landscapes. Cham: Springer.

Hutton, G., \& Haller L. (2004). Evaluation of the costs and benefits of water and sanitation improvements of the global level. Water, Sanitation, and Health, Protection of the Human Environment. World Health Organization, Geneva. WHO/SDE/WSH/04.04.

Montgomery, P., Ryus, C. R., Dolan, C. S., Dopson, S. \& Scott, L. M. (2012). Sanitary pad interventions for girls' education in Ghana: A pilot study. PLOS ONE, 7(10), e48274. doi: 10.1371/journal.pone.0048274

Morrissey, T. W., Hutchison, L., \& Winsler, A. (2014). Family income, school attendance, and academic achievement in elementary school. DevPsychol, 50(3), 741. doi: 10.1037/a0033848

Mustapha, A. K., Moses, M., \& Muhammad, C. (2017). Assessment of Toilet Facilities in Selected Secondary Schools within Maiduguri Metropolitan, North Eastern Nigeria. Journal of Natural Sciences Research, 7(10), 2224-3186.

NDHS. (2013). Nigeria Demographic and Health Survey. National Population Commission Federal Republic of Nigeria Abuja, Nigeria and ICF International Rockville, Maryland, USA. Retrieved from https://dhsprogram.com/pubs/pdf/FR293/FR293.pdf

Olukanni, D. O., Aridegbe, O.A., Awofeso, A. S., \& Ekwulugo, N. S. (2013). O. (2013) Assessment of wash program in public secondary schools in south-western Nigeria. ARPN Journal of Engineering and Applied Science, 8(3), 222.

Pilar, M., \& Brett, B. (2008). The school environment and adolescent well-being: Beyond academics. Retrived from https://eric.ed.gov/?id=ED503383 as accessed on 23/04/2018

Sommer, M. (2010). Putting menstrual hygiene management on to the school water and sanitation agenda. Waterlines, 268-278. doi: 10.3362/1756-3488.2012.008

UNICEF. (2011). WASH in schools monitoring package. Retrieved from https://www.unicef.org/wash/schools/files/wash_in_schools_monitoringpackage_.pdf

UNICEF. (2012). Water, sanitation and hygiene standards in child friendly schools manual. Retrieved from https://www.unicef.org/publications/files/Child_Friendly_Schols_Manual_EN_040809.pdf on 24/04/2018

UNICEF. (2015a). An assessment of menstrual hygiene management in secondary schools. Retrieved from https://www.unicef.org/nigeria/NG_publications_assessMHMNigeria.pdf on 23/04/2018

UNICEF. (2015b). Cholera outbreak in the in the West and Central Africa: Regional update, $2015-$ Week 29. Retrieved from reliefweb.int/report/Nigeria/cholera-outbreak-in-west-and central-africa- regional-update, 2015- week 29-enfr

UNICEF. (2018). UNICEF conveys key players in sanitation markets in West Africa. Retrieved from https://www.unicef.org/wca/press-releases/unicef-convenes-key-players-sanitation-markets-west-africa on $12 / 12 / 2018$

UNFPA. (2018). United Nations Population fund Nigeria. Retrieved from https://www.unfpa.org/data/NG on 29/03/2019

WHO. (2016). The Situation of WASH in schools in the pan-European region. ISBN 9789289 052047. Retrieved from https://www.euro.who.int/_data/assets/pdf_file/0020/322454/Situation-water-sanitation-hygieneschools.pdf?ua=1

WHO/UNICEF. (2016). Core questions and indicators for monitoring WASH in Schools in the Sustainable Development Goals. ISBN TBC (version November 2016). Retrieved from https://www.who.int/water_sanitation_health/publications/monitoring-wash-in-health-care-facilities-aug2018.pdf 
WHO/UNICEF. (2018). Drinking water, sanitation and hygiene in schools: global baseline report 2018. New York: United Nations Children's Fund (UNICEF) and World Health Organization.

\section{Copyrights}

Copyright for this article is retained by the author(s), with first publication rights granted to the journal.

This is an open-access article distributed under the terms and conditions of the Creative Commons Attribution license (http://creativecommons.org/licenses/by/4.0/). 